\title{
The most innovative lean practices deployed in transportation and their effects on the financial and operational performance
}

\author{
Mihaela Cornelia Popescu \\ Bucharest University of Economic Studies, Bucharest, Romania \\ Doctoral School of Business Administration \\ mihaela.popescu@fabiz.ase.ro
}

\begin{abstract}
The new lean paradigm defines the necessary management tools and techniques that create more value for the customers using lean resources. By reducing the non-value activities in one hand, and emphasizing on continuous improvement on the other hand, the lean practices implemented open the path for superior level of financial and operational performance. The purpose of this paper is to highlighting the strong correlation between the combination of the TQM, JIT, TMS, TPM and RFID as the most important lean practices employed by the transportation companies surveyed and its financial and operational performance. The correlation between the lean practices deployed within the transportation companies analyzed and their financial or operational performance has been established due to applying the SPSS quantitative methods, factor analysis and linear regression.
\end{abstract}

Keywords: lean practices, TQM, JIT, TMS, TPM, RFID, operational performance, financial performance, order management, shipping/ delivery management, on-road management.

\section{Introduction}

The purpose of lean practices implementation is to bring maximum of benefits to the customers by reducing unnecessary processes and activities, wasteful movement of materials or personnel and therefore, minimizing the costs. (Bhamu and Sangwan, 2014)

Empirical and exploratory studies reveal a series of quantitative and qualitative benefits of successful and continuous lean tools application. Many case studies and surveys fulfilled in the manufacturing sector become salient in proving the cost-benefit of improving the production lead time, product cycle time, inventory turnover, defects or manufacturing delays. Qualitative benefits include effective communication, improved rate of employee's retention, team building and common decision, supplier integration and Supply Chain visibility. (Bhamu and Sangwan, 2014) However, there are studies that contradict the effectiveness of lean implementation due to poor understanding of the implementation methodology or lack of performance measurement metrics. (Behrouzi and Wang, 2011; Browning and Heath, 2009) According to the results of the study the key successful factors in lean implementation refer to leadership, problem solving, financial capabilities, performance metrics, change management and continuous improvement training.

Recent studies have concluded that the new lean management practices redefined in the context of digitization had a huge impact on the company's business and operational performance. The results clearly demonstrate superior operational performance and waste elimination through implementing new IoT applications such as TMS (transportation management system) and RFID (radio frequency identification device) systems, ensuring flexibility, visibility, superior quality and order management high velocity. (Ahmad et al, 2003; Fullerton and Wempe, 2009; Shah and Ward, 2003) Although many articles and research papers have proved empirical evidence that the new technologies clearly respond to the lean principles and requirements, there is a lack of evidence regarding the benefits of the combination of practices on the operational and business performance. (Nawanir et al, 2012) 


\section{Literature review}

\section{Transportation lean practices and assessment issues}

The general term of "lean" was first time approached by the researchers from MIT, involved in the International Vehicle Program. The purpose of the project was to find important differences between the American and the Japanese automotive manufacturing systems. (Bhamu and Sangwan, 2014) Although the practices associated with the lean philosophy were being successfully applied in the Japanese automotive system, its names were shortly defined as Toyota Production System (TPS) or Just-In-Time (JIT). (Nawanir et al. 2012) The Japanese system has faced numerous changes along the way, being the global leader in implementing for the first time of a new statistical quality control management. (Spears, 2004; Dahlgaard and Park, 2006) According to Heizer and Render (2008) the terms JIT, TPS, and LM have the same meaning and application, moreover, the latter was being considered the Americanized version of the first two. (Nawanir et al. 2012) However, the new trend of automation and digitization changed the meaning of the term lean into a broader paradigm, incorporating more practices including the JIT and Total Quality Management.

In the context of large scale of globalization, the transportation industry requires certain lean practices able to respond to high volumes of freight demand. Large manufacturers, overwhelmed by the complexity of the transportation system, outsource this type of activity, "the burden" being passed on to the 3PL companies or to the logistics brokers. The new lean transportation management envisions those lean practices that properly fulfill lean principles and objectives, namely, reduced transportation cycle, zero claims and returns, visibility along the SCM, continuous improvement of communication and tracking capabilities of the shipment and also information management system. (Oleghe and Salonitis, 2016)

The new lean practices in transportation respond to the new trend of digitization by using advanced technologies from cloud applications to automated activities especially ones that involve shipping and receiving activities. The companies "leanness" is defined by the operational and financial performance, using certain metrics capable to quantify the effectiveness of the new practices introduced. (Neely, Gregory and Platts, 1995; Doolen and Hacker, 2005)

\section{Achieving financial and operational transportation performance through TQM, JIT, TMS, TPM, RFID practices application}

The transportation environment characterized by continuous increase in driver's shortage, imposed new hours of service regulations and higher velocity of product time cycle, entitle large shippers and transportation management companies to re-define and reframe the concept of lean thinking management and operation from an incremental perspective to a data- driven technologies point of view, with more control over the gaps and non-value activities, thus the chances of manifesting the lean phenomenon of muda being drastically reduced. However, successful lean implementation assumes proper combination of traditional TQM (total quality management), JIT (just-in- time) delivery and TPM (total preventive maintenance) practices with new technologies such as TMS and RFID. Literature had provided evidence of implementation failure due to inconsideration for lean practices as a total management system. (Fullerton and Wempe, 2009; Nawanir et al., 2012) There is no clear agreement among researchers and practitioners about the corresponding sets of practices under the same principles or lean objectives. The practices selected depend mostly on the industry insights and the researchers goals. (Shah and Ward, 2007; Nawanir et al., 2012) However, there is a common view regarding the lean manufacturing practices that ensure the fulfillment of the pull and flow principles, zero 
defects and supplier integration. The operational performance is influenced by the level of implementation of manufacturing lean practices including employee empowerment (Ramarapu et al, 1995; Chong et al, 2001; Taj and Morosan, 2011; Yang et al., 2011), Kanban (Lee and Paek, 1995; Sakakibara et al., 1997; Ahmad et al, 2004; Shah and Ward, 2007; Fullerton and Wempe, 2009; Yang et al., 2011), Total Quality Control and Management (Olsen, 2004; Shah and Ward, 2007; Dal Pont et al., 2008; Rahman et al, 2010; Yang et al, 2011), setup time reduction (Ahmad et al, 2004; Shah and Ward, 2007; Hallgren and Olhager, 2009; Fullerton and Wempe, 2009; Yang et al., 2011), TPM (Chong et al., 2001; Fullerton et al., 2003; Shah and Ward, 2007; Abdallah and Matsui, 2007; Yang et al., 2011) and JIT delivery (Shah and Ward, 2007; Fullerton and Wempe, 2009; Yang et al., 2011; Nawanir et al., 2012).

The new lean principle deployed within the entire Supply Chain regardless the industry involved, reclaims for the visibility and data sharing as the strong pillars of the pull system. By introducing the RFID, TMS and other cloud applications, companies are in the position of informing in proper time their suppliers about the customers' demands and requirements, reducing the gaps in important areas such as order management, transportation planning and execution, JIT shipping and delivery and cost reduction. (Fisher, 2018; Robinson, 2018)

In opinion of Venkatraman and Ramanujam (1986) business performance consists in a set of general concept regarding the company's effectiveness. In their opinion business performance comprises two major components, namely, financial measures and operational measures. According to Keats (1988), Dess and Robinson (1984), Venkatraman and Ramanujam (1986) financial performance include ROA, ROE, ROI, growth in revenues and market performance.

Total Quality Management (TQM) is a new management paradigm which emphasizes for continuous improvement in all processes and activities of an organization. Large portion of literature is dedicated to the main practices which ensure great level of quality at all levels of the company. (Garvin, 1988; Sink and Keats, 1982; Deming, 1993) There is a common agreement that total quality cannot be achieved unless practices such as employee training and commitment, shipper-carrier cooperation, improved traceability and visibility and departments' cooperation are not implemented. Going back to the eight basic types of waste such as overproduction, excessive stock movement, defective products and services, extra incurred transportation costs and logistics, waiting time, inefficient employees' management or desynchronized processes, the new lean approach characterized by digitization and automation expend and reintegrate the old Japanese practices of TQM and JIT by increasing the operations' quality and speed. (Leyh, Martin and Schaffer, 2017)

Just-in time (JIT) was a lean practice developed by Mr. Taiichi Ohno, the vice-president of Toyota Motor Company, being defined as the system that provides the right product, in the right quantity at the right time. (Sugimori, Kusunoki, Cho and Uchikawa, 1977) There is no clear agreement upon the classification of the JIT techniques identified in the literature. However, the studies of Kaynak and Bimmerle (1993) identified four categories of JIT strategies applied in the manufacturing sector referring to implementation and performance measures, supplier integration and employee empowerment. In the extent to the transportation industry, the most common JIT practices recognized by the scientific environment refer to JIT delivery, TQM and preventive maintenance. (Ben- Daya and Akram, 2013) The adoption of "just-in-time" delivery model in transportations and logistics implies complex strategies of shipping and delivery planning taking into consideration all the factors that might affect route optimization and reduced route cycle time. (Lukinskiy et al., 2013, Ansari and Modarress, 1986; Schonberger and Gilbert, 
1983) The JIT model application proved certain benefits in transportation operations management and also financial benefits.

Logistics magazine reveals that transportation management accounts 50\% of a company's average cost. Insufficient control over visibility, tracking, safety, order fulfilling and drivers 'management will lead to increase in time lead and costs.

According to the research made by Cerasis editors, "beyond a transactional tool, a TMS is now a PICBE | 162 strategic continuous tool."

For shippers dealing with multimodal transportation, each step of the shipment can become more stressful, given the fact that the TMS is mainly set for domestic and LTL deliveries, with no air or vessel type of transportation solution.

The main features of the new system rely mostly in optimized capacities of tracking shipments through the entire freight journey, improving the last-mile operations having constant feedback from the drivers. According to many transportation practitioners, the use of the new versions of TMS provides freight insights, improves visibility, monitors the filling order processes from order planning, shipment loading, routing, safety, unloading, shortages and claims to drivers' reliable way of communication and retention. When certain problems arise, TMS allows logistics companies to locate the gaps created and prevent future issues from happening. The new TMS increases the velocity of dock processes and activities reducing the risk of fees due to detention time applied.

The new TMS comprises strategic functions and features increasing the efficiency in endto-end transportation order, intelligent route optimization, and accuracy on issued invoices. Large transportation companies have reported clear benefits of TMS use in the freight procurement department by managing higher biding capacities added by superior integration of contracts in the planning and payment functions. Certain functions of TMS allowed large shippers to be aligned with the attributes of "shipper-of-a-choice" by better forecasting capacities, increasing the possibility of better load planning and therefore superior communication with carriers. (Paton and Brown, 2011) The benefits of TMS implementation are being reflected in superior operational and financial performance.

Total Preventive Maintenance (TPM) refers to preventive management of the equipment, machines, tools and fleet. The management technique put a lot of emphasis in empowering people from all management levels to adopt and take preventive actions in the purpose of improving the productivity. The preventive maintenance assumes the $5 \mathrm{~S}$ tools along with important foundation pillars such as planned and fleet maintenance, drivers' training for safety. The TPM practice positively influences transportation performance variables such as transportation order fulfillment, on-time shipping and delivery and also financial variables. (Schonberger, 1982a, Suzaki, 1987)

The RFID (radio frequency identification device) system is very useful in transportation and warehouse management, covering important needs such as identifying the products, locating and tracking the freight and temperature capabilities in case of temperature control loads.

According to Ferrer et al. (2010), the RFID use reflects its benefits over the important lean objectives such as quality, speed, flexibility and cost. By increasing the tracking capabilities the companies are in the position of better control of the distribution and transportation activities, with great positive impact on the transportation order fulfillment variables. Reducing the transportation cycle-time of a product means increase in speed and volume and therefore, obtaining larger revenues with less cost. (McAfee and Brynjolfsson, 2012, Chow et al., 2006; Banks et al., 2007) 
Therefore, based on the literature reviewed, the following research questions were formulated:

Q1: There is any positive correlation between the level of JIT, TQM, TPM, TMS and RFID implementation and the rate of growth registered by the transportation companies?

Q2: There is any positive correlation between the degree of JIT, TQM, TPM, TMS and RFID use and transportation operational performance?

\section{Research methodology}

\section{Transportation variables description}

Transportation operation management is divided in several sub-sets of transportation activities, starting with order management (1), transportation procurement and planning (2), warehouse management (3), shipping-receiving execution (4), on-road management (5) and delivery management (6). The performance measures of these dependent variables were established using also the Lickert scale, the managers interviewed being asked to evaluate the performance on a scale from 1 to 5 (1- poor; 2- needs improvement; 3- satisfactory; 4-good; 5- very good). Other important dependent variable used was the average rate of growth obtained from the moment of lean practices implementation. Using also the Lickert scale, the evaluation was the followed: 1decrease in rate growth, 2 - up to $10 \%$ increase, 3 - up to $20 \%$ increase, 4 - up to $30 \%$ increase, 5 up to $40 \%$ increase, 5 - up to $50 \%$ increase and more.

In order to demonstrate that the higher degree of lean practices use, the higher operational and financial performance companies achieve, I conducted a survey in the purpose of ranking the transportation companies according to their level of lean practices implementation. The managers who answered the survey provided information regarding the level of JIT, TQM, TPM, TMS and RFID use for each set of transportation activities. The level of aforementioned lean practices was evaluated using the Lickert scale from 1 to 5 (1- not use, 2- practice used in warehouse management (3), shipping and receiving(4) and delivery activities (6) 3-practice used in (3), (4), on-road activities (5) and (6); 4-practice used in transportation planning and (3), (4), (5), (6); 5- practice used in order management(1) and (2), (3), (4), (5), (6).Therefore, the JIT, TQM, TPM, TMS and RFID are considered the independent variables. Factor analysis was applied for defining the most influential lean practices in the transportation industry. The correlation level between the independent and dependent variables was established due to bivariate regression application. Therefore, the variables were denoted as follows:

1. JIT, TQM, TPM, TMS and RFID as independent variables- numerical denoting from 1 to 5.

2. (Order) management (1), Transportation and (Planning) (2), (Warehouse) Management (3), (Shipping) and Receiving (4), (On road) activities (5), (Delivery) activities (6) as dependent variables - numerical denoting from 1 to 5 .

The survey was redirected to important managers and practitioners selected from the companies that already reach a certain point of lean implementation. From the 64 surveys sent by e-mail to managers from different transportation companies, only 36 have managed to answer, the response rate being $56 \%$. 


\section{Research findings}

\section{Factor analysis results}

Factor analysis was used to identify factors that explain the patterns of correlations within the independent variable chosen. The method of factor extraction employed in the research is the Principal Component Analysis. I took into consideration 5 variables defining the new trend of lean practices used in transportation. The descriptive statistics for the group variables is shown in Table 1, all the variables having a mean score greater than 2 meaning that all lean practices are being applied as a whole at least in the first three categories of transportation processes, namely order management (1), transportation and planning (2) and warehouse management (3). The highest mean was depicted in TMS application explaining that transportation performance is reached through digitization and investment in new technologies. The standard deviation of the data is lower than the mean implying the reliability of the model. Factor analysis was discussed with communalities output indicating the amount of variance in each variable that is accounted for, before and after extraction.

Table 1. Descriptive Statistics for the independent variables

\begin{tabular}{lr|r|r} 
& \multicolumn{1}{c|}{ Mean } & Std. Deviation & Analysis N \\
\hline JIT & 2.61 & .599 & 36 \\
\hline TQM & 2.17 & .447 & 36 \\
\hline TPM & 2.61 & .549 & 36 \\
\hline TMS & 3.75 & .500 & 36 \\
\hline RFID & 2.08 & 1.105 & 36 \\
\hline & & &
\end{tabular} Source: author's own research

Tables $2 \mathrm{a}, 2 \mathrm{~b}$ and $2 \mathrm{c}$ present the communalities between all factors analyzed. The extraction values corresponding to each variable are very high from 798 to 539 indicating that data collected was good for the research and factors well defined.

Table 2- Correlation matrix of independent variables

2.a. Communalities

\begin{tabular}{c|r|r} 
& Initial & Extraction \\
\hline JIT & 1.000 & .716 \\
\hline TQM & 1.000 & .745 \\
\hline TPM & 1.000 & .539 \\
\hline TMS & 1.000 & .732 \\
\hline RFID & 1.000 & .798 \\
\hline
\end{tabular}




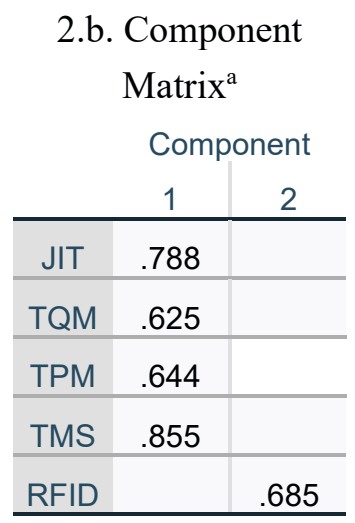

PICBE $\mid 165$

2.c. Total Variance Explained

\begin{tabular}{|c|c|c|c|c|c|c|c|c|c|}
\hline \multirow[b]{2}{*}{ Component } & \multicolumn{3}{|c|}{ Initial Eigenvalues } & \multicolumn{3}{|c|}{$\begin{array}{c}\text { Extraction Sums of Squared } \\
\text { Loadings }\end{array}$} & \multicolumn{3}{|c|}{ Rotation Sums of Squared Loadings } \\
\hline & Total & $\begin{array}{c}\% \text { of } \\
\text { Variance } \\
\end{array}$ & $\begin{array}{c}\text { Cumulative } \\
\% \\
\end{array}$ & Total & $\begin{array}{c}\% \text { of } \\
\text { Variance } \\
\end{array}$ & Cumulative \% & Total & $\begin{array}{c}\% \text { of } \\
\text { Variance } \\
\end{array}$ & $\begin{array}{c}\text { Cumulative } \\
\% \\
\end{array}$ \\
\hline 1 & 2.486 & 49.725 & 49.725 & 2.486 & 49.725 & 49.725 & 1.815 & 36.310 & 36.310 \\
\hline 2 & 1.045 & 20.893 & 70.618 & 1.045 & 20.893 & 70.618 & 1.715 & 34.308 & 70.618 \\
\hline 3 & .724 & 14.487 & 85.105 & & & & & & \\
\hline 4 & .454 & 9.074 & 94.179 & & & & & & \\
\hline 5 & .291 & 5.821 & 100.000 & & & & & & \\
\hline
\end{tabular}

Source: Author's own research

Table $2 \mathrm{a}$ shows the most significant variables that define the transportation performance. The variables with the most influence on the transportation performance are TMS (.855), JIT (.788) and RFID (685) covering $85.1 \%$ of cumulative variance ( $2 \mathrm{~b}$ and $2 \mathrm{c}$ ). However, the scores above .600 for the other two variables (TQM and TPM) reveal higher level of correlation between all independent variables; therefore, all will be used in further analysis. The KMO value of .649> .500, the significance coefficient of .000 and Eigen value higher than one prove the reliability of the model.

\subsubsection{Correlation matrix results}

The Pearson correlation has been applied using the aforementioned independent and dependent variables. The correlation matrix as appears in Table 3 reveals strong positive correlation between the lean practices and the performance level registered in all the transportation sectors.

Table 3- Pearson correlation between independent and dependent variables

\begin{tabular}{|l|l|l|l|l|l|l|l|}
\hline $\begin{array}{l}\text { Correlation/ } \\
\text { Significance }\end{array}$ & Growth & $\begin{array}{l}\text { Order } \\
(1)\end{array}$ & $\begin{array}{l}\text { Planning } \\
(2)\end{array}$ & $\begin{array}{l}\text { WHM } \\
(3)\end{array}$ & $\begin{array}{l}\text { Shipping } \\
(4)\end{array}$ & $\begin{array}{l}\text { On- } \\
\text { road } \\
(5)\end{array}$ & $\begin{array}{l}\text { Delivery } \\
(6)\end{array}$ \\
\hline JIT & .657 & .565 & .553 & .409 & .599 & .595 & .409 \\
\hline
\end{tabular}




\begin{tabular}{|l|l|l|l|l|l|l|l|}
\hline & .000 & .000 & .000 & .013 & .000 & .000 & .013 \\
\hline TQM & .602 & .399 & .409 & -.037 & .178 & .359 & .420 \\
& .000 & .016 & .013 & .832 & .298 & .032 & .011 \\
\hline TPM & .357 & .391 & .318 & .387 & .363 & .075 & .352 \\
& .033 & .018 & .059 & .020 & .030 & 707 & .035 \\
\hline TMS & .643 & .658 & .667 & .376 & .637 & .428 & .615 \\
& .000 & .000 & .000 & .024 & .000 & .009 & .000 \\
\hline RFID & .181 & .471 & .456 & .554 & .505 & .145 & .201 \\
& .290 & .004 & .005 & .000 & .002 & .398 & .240 \\
\hline
\end{tabular}

PICBE $\mid 166$

Source: Author's own research

The regression model reveals three important lean practices that define the high level of growth of the transportation companies surveyed. There is a strong positive correlation between JIT practice and the growth indicator $(.657$, significance $.000<.05)$ which clearly demonstrates that Just-in time practice applied at all level of transportation activities brings superior financial performance. High level of strong positive correlation it is demonstrated between TQM practice and growth rate $(.602$, significance $.000<.05)$ which imply that transportation companies usually combine the JIT and TQM practices for better financial results. (Kaynak, 1996; Dion et al. 1992a) The latest versions of the digitized TMS prove huge benefits on the transportation companies' financial performance. The TMS variable has a strong positive influence on the growth rate $(.643$, significance $.000<.05)$, giving the transportation industry the "attribute" as the "fastest growing enterprise markets". (Extracted from Cerasis, 2016) The new versions of TMS incorporate freight tracking and tracing functions, transportation planning and execution covering some of the features that characterize TPM and RFID practices. This fact explains the poor correlation between the financial indicator and the other two lean practices, namely TPM and RFID. Therefore, the regression model offers a positive answer to the first research question.

Referring to the operational performance, JIT and TMS has the highest positive influence on the variables such as Order management (JIT- .565, sig.- .000, TMS- .658, sig. - 000), Planning (TMS-.667, sig.- 000), Shipping/ Receiving (JIT- .599, sig.- 000, TMS- .637, sig.000), On-road (JIT- .595, sig. 000) and Delivery (TMS- .615, sig. 000). The RFID system proves its strong positive correlation with warehouse management (.554, sig.000) and shipping and receiving processes $(.505$, sig. $002<.05)$ influencing the loading/unloading time and paperwork accuracies. In regard to operational performance the second research question has a positive response.

\section{Discussion}

Transportation is one of the weak points in logistics covering high costs and many wasteful activities. These facts lights out the necessity of lean management implementation based on the new advanced technologies combined with traditional ones such as JIT or TQM. The JIT delivery model was the research topic for many scholars and practitioners, offering mathematical and empirical results of implementation and its benefits on important transportation KPIs, converging with the results obtained in the present research. (Lukinskiy et al., 2013, Kaynak, 1996) According to Anh and Matsui (2007) the success of JIT implementation and its benefits on the financial indicators is confirmed when is realized in combination with TQM practice. However, the present research proved that transportation companies rely mostly on JIT practices itself, the quality management being assured by the new TMS. (Advisory Group CorporationAGC) 
The results provided by the correlation matrix clearly demonstrate that TMS is a very important tool for assessing the company's operational and financial performance. By using the TMS tool and practice, companies have the chance to increase the velocity of transportation processes, to enlarge the transportation network, to coordinate multiple shipping assignments, to analyze the best rates, route options, to select shippers' partners following the "shipper of a choice" principle. According to the research of AGC, the TMS lean practice improves order management activities by $58 \%$, increase shipment visibility up to $100 \%$, optimizes the activities within on-road management by $52 \%$ and increases the driver retention indicator up to $60 \% .{ }^{1}$

The present paper reveals the importance of RFID application in the warehouse management and also in the shipping/receiving processes. The strong positive correlation between the RFID system and the aforementioned transportation variables confirms the results of Nikolicic et al, (2015) and Doan, (2017), the scholars proving reduced transportation cycle time by $49 \%$. The study of Swedberg (2010) proved considerably reduced shipping time with more paperwork accuracy and increase in general loading/unloading operational performance. Although the present study did not confirm the correlation between RFID and the financial indicators, the research of Chen, Cheng and Huang (2013) indicates strong positive influence of RFID application in Supply Chain and logistics, especially on return on investment indicator. Therefore, the limitations of the present research entitle the author for further investigation on how RFID implementation influences other performance financial indicators.

\section{Conclusion and further research}

The present research emphasizes the new trend in framing a sustainable transportation business paradigm, namely the digital freight matching through which advanced technologies and cloud applications link different transportation needs of shippers, carriers and other transportation providers. The upgraded TMS and RFID systems help companies to ease the issues related to driver shortage and capacity crunch, facilitating better connection with strategic partners. According to De Muynck, the vice president of Gartner research platform the digitization of freight industry has not a disruptive influence on the transportation overall, as Uber was for the taxi industry, in contrary it came up like a complementary solution for shippers and transportation key players to keep themselves on the loop. As he mentioned "...Comparing the freight market to a pie... as more players are carving off larger slices for themselves, the pie itself is growing exponentially."

However, there are certain limitations on the present paper, due to limited number of companies surveyed. The research will also be expanded in the purpose of taking into consideration other important financial and operational indicators such as return on investment, turnover, the companies' size and scope, demand forecasting, paperwork processing, claims and driver retention. Further studies will include cost/benefit analysis of each lean practices implemented in the transportation industry.

\section{References}

Abdallah, A.B. \& Matsui, Y. (2007). JIT and TPM: their relationship and impact on JIT and competitive performances. Conference of the International Decision Sciences Institute (DSI), Bangkok, Thailand, July 13

\footnotetext{
${ }^{1}$ Extracted from Cerasis magazine, 2016
} 
Ahmad, S., Schroeder, R.G., \& Sinha, K.K. (2003). The role of infrastructure practices in the effectiveness of JIT practices: implications for plant competiveness. Journal of Engineering Technology Management, 20, 161-191

Anh, P. C., \& Matsui, Y. (2007). Effect of Total Quality Management and Just-In-Time practices on Competitive Performance - Empirical Evidence. POMS 18th Annual Conference, Dallas, Texas, U.S.A.

Banks, J., Hanny, D., Pachano, M. A., \& Thompson, L. G. (2007). RFID Applied. John Wiley \& Sons, Inc.

Behrouzi, F., \& Wong, K.Y. (2011). Lean performance evaluation of manufacturing systems: a dynamic and innovative approach, Procedia Computer Science, 3(1), 388-395

Ben-Daya M., \& Akram M (2013). Third party logistics risk management. In proceedings of 2013 International Conference on Industrial Engineering and Systems Management (IESM), 1-10

Bhamu, J., \& Sangwan, K. (2014). Lean manufacturing: literature review and research. International Journal of Operations \& Production Management, 34(7), 876-940

Browning, T.R., \& Heath, R.D. (2009). Reconceptualizing the Effects of Lean on Production Costs with Evidence from the F-22 Program. Journal of Operations Management, 27(1), 23-44.

Chen, J.C., Cheng, C-H., \& Huang, P.B. (2013). Supply chain management with lean production and RFID application: a case study. Expert Systems with Applications, 40, 3389-3397

Chow, H.K.H., Choy, K.L., Lee, W.B., \& Lau, K.C. (2006). Design of a RFID case-based Resource Management system for warehouse operations. Expert Systems with Applications, 30, 561-576

Dahlgaard, J., \& Park, S. (2006). Lean production, Six Sigma, TQM and company culture. The TQM Magazine, 18(3), 263-281.

Doan, B. (2017). Radio frequency identification (RFID) and its impacts on logistics activities. International business.

Doolen, T.L., \& Hacker, M.E. (2005). A review of lean assessment in organizations: an exploratory study of lean practices by electronics manufacturers, Journal of Manufacturing Systems, 24(1), 55-67

Ferrer. G., Dew, N., \& Apte, U. (2010). When RFID right for your service? International Journal of Production Economics, 124, 414-425

Fullerton, R.R., \& Wempe, W.F. (2009). Lean manufacturing, non-financial performance measures, and financial performance. International Journal of Operations \& Production Management, 29 (3), 214-240

Hallgren, M., \& Olhager, J. (2009). Lean and agile manufacturing: external and internal drivers and performance outcomes. International Journal of Operations \& Production Management, 29 (10), 976-999

Heizer, J. \& Render, B. (2008). Operations Management. Pearson Prentice-Hall, Upper Saddle River, NJ

Kaynak, H., \& Bimmerle, C. F. (1993). Empirical research in just-in-time management. Proceedings of the Southern Management Association, Atlanta, Georgia, 331 334

Keats, B. W. (1988). The vertical construct validity of business economic performance measures. Journal of applied Behavioral Science, 24, 151-160.

Leyh, C., Martin, S., \& Schaffer, T. (2017). Industry 4.0 and lean production- A matching relationship? An analysis of selected industry 4.0 models, Federated Conference on Computer Science and Information Systems (FedCSIS), https://doi.org/10.15439/2017F365

Lukinskiy V. S., Pimonenko M. M., Paajanen M., \& Shulzhenko T. G. (2013). Development of Methodology and Tools for Comparative Assessment .of Operational Efficiency of KPI-based Logistical Infrastructure Facilities. Transport and Telecommunication, (3): 223-229 
Mirdad, W.K., \& Eseonu, C.I. (2015). A conceptual map of the lean nomenclature: comparing expert classification to the lean literature. Engineering Management Journal, 27 (4), 188202

Nawanir, G., Teong, L.K., \& Othman, S.N. (2012). Impact of lean practices on operations performance and business performance. Some evidence from Indonesian manufacturing companies. Journal of Manufacturing Technology Management, 24(7), 1019-1050

Nikolicic, S., Kilibarda, M., Atanaskovic, P., \& Ivanisevic, A. (2015). Impact of RFID Technology on logistic process efficiency in retail supply chains. Promet-Traffic \& Transportation, 27 (2), 137-146.

Oleghe, O., \& Salonitis, K. (2016). Variation modeling of lean manufacturing performance using fuzzy logic based quantitative lean index. 48th Conference on Manufacturing System.

Schonberger, R. J. (1982a). Japanese manufacturing techniques: Nine Hidden lessons in simplicity. New York, N.Y.: The Free Press

Spear, S.J. (2004). Learning to lead at Toyota. Harvard Business Review, 5, 78-86.

Sugimori, Y., Kusunoki, K., Cho, F., \& Uchikawa, S. (1977). Toyota production system and kanban system, materialization of just-in-time and respect-for-human system. International Journal of Production Research, 15, 553-564.

Suzaki, K. (1987). The new manufacturing challenge: Techniques for continuous improvement. New York, N.Y.: The Free Press.

Swedberg, C. (2008). Clothing designer brings RFID to its shippers. RFID Journal, December 5

Taj, S., \& Morosan, C. (2011). The impact of lean operations on the Chinese manufacturing plants. Journal of Manufacturing Technology Management Accounting, 19 (2), 157-168

Wamba, S.F., Anand, A., \& Carter, L. (2013). RFID Applications, issues, methods and theory: a review of the AIS basket of top journals. Proudio Technology, (2013), 9,421-430.

https://www.tmw.suite

https://www.FleetOwner.Com

https://www.logisticsmgmt.com/article/transportation_best_practices_trends_make_me_a_match /motorfreight 